Università degli Studi di Salerno

Centro di Economia del LaVoro e di Politica Economica

\author{
Gianluigi Coppola* - Maria Rosaria Garofalo** \\ Fernanda Mazzotta***
}

\title{
INDUSTRIAL LOCALISATION AND \\ ECONOMIC DEVELOPMENT. \\ A CASE STUDY
}

*glc@xcom.it - ** garofalo@unisa.it - *** mazzotta@unisa.it

CELPE Centro di Economia del Lavoro e di Politica Economica

DISES Dipartimento di Scienze Economiche e Statistiche

Università degli studi di Salerno

Via Ponte Don Melillo - 84084 Fisciano (Salerno) Italy www.celpe.unisa.it

DISCUSSION PAPER NUM. 71

Settembre 2002 
Centro di EConomia del Lavoro e di Politica EConomica

Comitato Scientifico:

Adalgiso Amendola, Floro Ernesto Caroleo, Ugo Colombino,

Cesare Imbriani, Pasquale Persico, Enrico Pugliese, Salvatore Vinci 
Abstract $\quad 5$

Introduction 6

1. The literature: some ideas 8

2. The manufacturing industry of the province of Salerno 14

2.1 The territory and the Local Labour Market System of the province of Salerno 14

2.2 The LLMS specialization indexes 16

2.3 Micro Areas (groups of municipalities) specialized in manufacturing. A cluster analysis 19

3 Institutional factors in the specialized areas 25

3.1 The data 26

$\begin{array}{ll}3.2 \text { The variables } & 27\end{array}$

4. Correspondence analysis: results 31

5. Conclusions 37

6. References 39

7 Appendix 41 


\section{Abstract}

The research described in this paper is consisting of an indepth study of an important area of the Italian Mezzogiorno: the province of Salerno. The aim of the paper is twofold. The first was to identify, by means of cluster analysis, specialization of industrial areas in this province For that, some methodological points are previously selected from the current approach to development economics, that focuses both on genesis and evolution of local systems, by emphasising, among other aspects, the role of the immaterial resources and institutions. The results depict a variegated territory comprising both areas of closed economy, where the purpose of economic activity is to satisfy basic needs (food and housing), and areas that display a certain degree of economic openness towards the outside markets. Many clusters with high indexes of manufacturing specialization are classified as areas of sub furniture or as areas born by an exogenous intervention. The second aim of the research is to measure the social conditions that should foster the growth of new industrial districts within different areas of productive specialization, just identified by the cluster analysis. The approach used was the simple correspondence analysis of a set of qualitative variables surveyed, by a questionnaire given to 462 businesses in the province of Salerno.

Keywords: Industrialization; Local Labour Market; Regional and Urban Analysis; Correspondence Analysis - JEL classification codes: O14; 018; C10 


\section{Introduction ${ }^{1}$}

One of the most important social and economic Italian problem is the underdevelopment and the lower levels of industrialisation of the Southern part of the Country. Since the first years of post war world II, many Government interventions have been token place in order to encourage the localisation of firm in this big area. Particularly at the end of the years ' 50 , in concomitance with the phase of strong expansion of the big industry in the Northern Italy, the Government choice was to encourage the localization of big firm in the area in order to employ as many workers as possible.

The most important characteristics of this kind of industrialization were mainly: 1) an elevated quota of investment made by state-controlled firms; 2) the localitation of new industries not belonging to the southern tradition, most of the them capital intensive, as the aeronautical industry, and the telecommunications, 3) a transfer process of production sites to the South made by the Northern firm even if many directional centres remanded out from the Southern territory. In the following decades and particularly from the middle of' 70 s, the end of the fordism model, and with it the constant decline of the big industry has redrawn the Italian economic geography. In those years the cluster of small and medium firm emerged and they caused the economic growth of many Italian geographical areas that covered a secondary importance role as, for example, the regions of Veneto and Marche.

But of the 199 industrial districts censed by the ISTAT (National Institute of Statistics) in the 1991, only 15 - equal to the $8 \%$ of the total - resulted have been located in the South Italy

\footnotetext{
${ }^{1}$ This study has been made inside the project OPIS (Permanent Observatory of the Enterprises of the Province of Salerno) financed by the Foundation CaRiSal and inside the DISES Project on "Monitoraggio di un sistema locale di imprese". Although written jointly by the three authors, the second section may be attributed to Maria Rosaria Garofalo, the third to Gianluigi Coppola and the fourth to Fernanda Mazzotta.
} 
(ISTAT, 1996). In this different scenario, also the analysis approach on the lower levels of industrialization has changed.

After that the scarce presence of industrial districts in the southern and insular area has been pointed out, the attention has been focus to see if there were early stages industrial districts in in this part of Italy, or if there exist, at least, those environmental and social conditions- well evidenced from the wide literature on the industrial districts - for favor the birth and the development of such industrial agglomerations also in the Mezzogiorno.

In fact it is possible that in the Mezzogiorno, the Local Labour Market Systems in which the number of agglomerations of small firms operate, is higher than those identified and "that it may depend on a higher quota of the services sector of the southern cities and also on the presence of shadow economy that characterizes the small and medium southern firms." (Brusco Paba, 1997) The same authors conclude affirming the need to investigate on the industrial reality of the Mezzogiorno through studies on the field.

With the asserting of the post-fordism paradigma, the philosophy of support for the Mezzogiorno has changed. It was direct to favour the development of the local resources instead tha settlement of big firms. As it will be underlined in the next paragraphs, the several policy for the Mezzogiorno have left evident marks on the territory even if they didn't always obtained the planned effects.

This research is a detailed study of Salerno's productive reality, implemented also trough a direct survey on the local firms. Using Intermediate Census of the Industry and of the Services (CIIS, 1996) data, the specialization indexes of the Local Labour Market System of the province of Salerno have been calculated in order to individualize high manufacturing specialization areas. Subsequently, applying a cluster analysis, the existence of micro areas of specialization has been also tested.

Nevertheless the industrial districts areas have been charatherized also by the existence of historical, cultural, social and political factors, besides high manifactured specialization index. Therefore the attention could not be exclusively focused on the productive structures, but it must also take into account of the 
institutions, of the social network existing in the area, and of the mechanisms of interaction between productive structures and social framework (Brusco, Paba, 1997). Most factors are qualitative type, and hence they are difficult to measure and to quantify. To such difficulty one obvious, frequently, through the study of cases of specific areas, with interviews directed to entrepreneurs and privileged actors (Viesti, 2000).

In order to obtain those qualitative variable, an in-depth questionnaire has been administered to 462 enterprises of the province of Salerno, and trough a simple correspondence analysis, those variables have been extract. The objective is to cross the clusters areas, individualised with the cluster analysis presented in the third paragraph of this paper, with the latent variables obtain with the simple correspondence analysis. The final result is to check the existence of those institutional factors, that have been considered like fundamental for the develop of the industrial districts, in those micro areas of specialisation.

\section{The literature: some ideas}

Our case-study is carried on in the rising debate from the first half of Seventies, germane to the "anomalies", both structural and political-normative, of industrial development pattern in Italy (see Barca and Magnani 1987; Bellandi, Becattini, Dei Ottati and Sforzi eds, 2001, among many others authors), that - starting from either the crisis of large size firms or the failures of traditional incentives apparatus for Mezzogiorno - is characterized, at the current, by a non-convergence path towards the most advanced countries, based, essentially, on a virtuous mix of firms of different scale.

This debate is intended, namely, to explain the medium-long run performances of Italian economy in terms of local development systems (Brusco and Paba 1997; Signorini, 2001) by stressing two following features. (i) By deciphering both the endogenous economic sources and the political induced forces of the genesis, reproduction and competitiveness of these local systems; and (ii) 
by focusing, in particular, on the dominance of small and mediumsmall firm (by number and dimension) as well as their agglomeration, that are investigated, essentially, on the basis of the ability to produce and sustain complementarities (Ray 1998) trough new productive linkages and integration processes among different areas.

As well known, this literature is growing more and more, and, above all, seems to be heterogeneous, because it makes up a bundle of descriptive investigations, comparative analyses and provisional theoretical frameworks. For our purposes, we don't provide a complete survey of that; however, we decode it, shortly, in a way of a bifurcation in two main strands. The first one is centred on the idea of a top down process of decentralization and vertical disintegration of productive cycles outside: it mirrors the standard behaviour of large firms, that are supposed to modify their previously efficient capital/labour ratios just as a perfectly rational adaptation to exogenous changes in the markets of input.

On the contrary, the second strand is centred on the territorial structures of industrial development, starting from the direct knowledge of historical process of industrialization and its links to agricultural sector, and investigating on how labour/ credit/ capital markets are working at local level and, therefore, how many kinds of transactions are implemented, such that they are able to create the marshallian "social atmosphere" of an economy. By this way, the territorial structures are producing bottom up a (un)coordinated and (un)cooperative environment, that would be, alternatively, against or in favour of initiating and sustaining a local development path.

To summing up: the former strand is consistent with the mainstream economics, by which small and small-medium size firms represent a transitory phenomenon, passing from the old to a new cycle, whereas the large is still the competitive paradigm, like as in the dualistic approach. The latter strand seems to be heterodox, because it is taking into account, seriously, the local and disseminated abilities to produce and implement innovative knowledge, as a appositive reaction to the modified condition of external demand. In this sense, genesis and evolution of small and 
small-medium firms could constitute a persistent phenomenon, coherent to that variety of development paths, observable in Italy.

They are explained, namely, as a specific result of both horizontal integration process, new linkages of productive activities intra-area, and of beneficial complementarities gained from additional exchanges opportunities intra-area and inter-areas.

Moreover, the peculiar ways of production organization - i.e. the system of specialized firms that realize a localized division of labour - define only one of the two mutual features of initiating and reproducing a local system. The second one is defined, in fact, by the social institutional context, i.e. by the formal and informal rules that govern repeated reciprocal interaction intra-area, and that, in some ways, identify the incentives structure of an economy (North 1991).

In short, it seems methodologically correct to explain this literature as an evolutionary path: how ideas are born, how they have influenced policies, and in turn how they are changing according to their perceived successes or failures, could be explained by considering the (persistence of) development differentials in terms of specialization degrees and environmental/immaterial resources, as our case study witnesses (see $\S 4)$.

Within this second stylised approach, and even in spite of the plethora of models, it is possible, nowadays, to recognize some useful large generalizations relative to local development experiences - i.e. the class of "industrial districts" - and, more relevant for our aim, some general categories of analysis. In particular, we will refer to the category of flexible "marshallian capital": it includes, as mutually consistent forces of a local system, physical/technical equipment and natural resources, human capital, and social capital or social capability (Sen 1999). In addition, the entrepreneurial choices of innovation and the deeprouted political or cultural leadership on one hand, and the capability to accumulate endogenously the stock of that capital on the other hand play, respectively, the role of driving forces and propagator mechanism of a development process at local level. In other words, how differently the entrepreneurs are prone to perceive the additional opportunities, by creating linkages and 
complementarities among areas, matters to explain development differentials and, therefore, the persistence of less favourites or late-comer regions (Becattini et al. 2001).

If we compare this Italian literature on local system with updating approach to development economics, it will emerge a common sub-set of explanation: both emphasize the feasible, existing and potential, impacts of institutions on the medium-long run path of an economy. They are supposed to be able of impeding or favouring a virtuous circle between the process of capital accumulation (in marshallian sense), the entrepreneurial vitality ("animal spirits") and complementarities of activities and areas, creating in this way, positive externalities (Bardan 2000; North 1991; Ray 1998).

Again, for our purposes, we don't review all this complex literature, but we will select some relevant theoretical points, that can be outlined as follows: (i) the role of history versus expectations in initiating a new (good) development path (Krugman 1991; Ray 1998); (ii) the start-up costs to innovate and the entrepreneurial expectations (Ciccone and Matsuyama 1996; Matsuyama 1991); (iii) the appropriateness of a knowledge system and of an institutional apparatus at local level (Hausmann and Rodrick 2000; Rodrick 2002).

About point (i): starting from the marshallian hypotheses of positive external economies and increasing returns in production that generate cumulative growth (see also the endogenous growth paradigm), it follows that the geographical division into areas of different degree/quality of development is endogenously produced. The basic theoretical question - and subsequently its policy implications (see points ii and iii) - is to investigate which of the feasible multiple equilibria will be, in fact, selected and implemented or, in other words, which are the driving forces of a specific development path.

Like as in the traditional literature, history (tastes, technology, resources endowment and, in sum, geography) matters in order to promote and sustain a "circular causation" of a virtuous circle or underdevelopment trap. But a relevant problem consists in that these initial conditions are assumed "ad hoc". And like as in a particular strand of modern literature (discussed by Krugman 1991, 
among many others), positive entrepreneurial expectations about future returns to an investment represent the "big push" of an economy. However, since innovative investments are too costly, and because the beneficial effects of externalities are depending on the decisions of other agents, then "the willingness of firms to invest depends on their expectations that other firms will invest" (Krugman, p.654). the new equilibrium solution will be an outcome of "self-fulfilling prophecy". If in the reality "history" is most relevant than "expectations" or vice versa is not a general solution, but it depends on the specific circumstances of an economy and "in particular, on the costs of adjustments" (Krugman, p.666), and, more specifically, it depends on the transport costs, when necessary inputs are imported.

The choice of a long-run equilibrium solution becomes matter of policy, that is, essentially, to combat coordination failures of private expectations, to set up an appropriate incentive structure enabling firms to break free of initial conditions and, therefore, to produce positive agglomeration externalities (Ray 1998; Rodrick 2002). By this way, history will be matter again in the future. New ideas are provided by a new approach on relationship of geography and growth (Gallup, Sachs and Mellinger 1998).

About point (ii): following Ciccone and Matsuyama (1996) who distinguish different degrees of development systems according to how intensively the consumer goods industries use specialized intermediate capital goods, and how frequently they use a variety of costly producer services, then the critical point to remove underdevelopment trap is concerning the relationship of productivity growth and increasing specialization process. Again, like as in point (i), it is supposed a circularity (bad or good) in a development path and, in this case, a circularity between the degree of specialization and the market share of intermediate goods. Two are the factors underlying the development path of late-comer economies: the start-up costs and pecuniary externalities. "First, because of start-up costs, specialist firms that produce intermediate goods are subject to dynamic increasing returns. The inducement to start-up operations thus depends on the anticipated market size." Positive expectations on final demand are playing as a propagator mechanism of a virtuous circle. And 
second," starting-up a new firm and introducing a new variety of intermediate inputs generate benefits that are not completely appropriate to those who finance start-up costs" (Ciccone and Matsuyama, pp.34-35).

What is crucial in this model is the existence of a "threshold in economic development": if economies are below this critical level, then entrepreneurial vitality is not a sufficient condition to initiate a new development path: that is because the expectations of entry firms will be not coordinated and, therefore, not self fulfilled ex post. Many reasons are open, therefore, for policy intervention: in particular, the coordination failure is costly for an economy (because it produce negative externalities), a huge of resources are required to be reallocated from production and, in turn, the resources endowment is a constraint in the poor economies. Then, the level both of productivity and specialization will be still low (vicious circle). The theoretical and political attention is pointed out on "the critical roles played by the availability of intermediate inputs and producer services" (Ciccone and Matsuyama, pp.58).

Finally, about point (iii): Rodrick and Hausmann (2002) and Rodrick (2002), among many others, suggest a non-deterministic approach of political reform and institutional design to support development economics, like as, on the contrary, it is assumed in the two last decades of neoclassical growth theory, founded on the simply hypotheses of "foreign technology" and "good institutions". From this old theoretical perspective, it will be generated a political consensus in terms of, respectively, openness of an economy and governance rules against corruption. But, initiating a new development path has not a deterministic solution, neither in terms of resources endowment nor in terms of induced policy (see point (i) and (ii)). According to many factual "anomalies" of development process - observable cross-country - the challenge of this new perspective consist in inducing bottom-up a process of "selfdiscovery" of the future path of specialization i.e. in a process of learning about what are the investments that are "appropriate at local level". 


\section{The manufacturing industry of the province of Salerno}

2.1 The territory and the Local Labour Market System of the province of Salerno

Those who set out to quantify and analyse an area's levels of specialization and industrialization must make two fundamental choices: (i) the geographical unit of reference, and (ii) the levels at which the productive sectors for which they intend to calculate the specialization indexes should be disaggregated. With regard to the former of these two choices, the most frequent practice in the literature, and also at the legislative level, is to use Local Labour Market Systems (henceforth LLMSs) as the reference geographical areas for calculation of levels of specialization.

LLMSs can be defined as aggregations of territorial units comprising homogeneous labour markets, or in other words, geographical areas in which labour demand and supply overlap. As regards the classification of economic activities, re-aggregating productive sectors in different manner yields very different results. Used for the research described here was the 1991 ATECO threedigit classification, although others were possible.

The province of Salerno covers a surface area of around 5000 square kilometres and has a population of 1,091,991 inhabitants. Its 158 municipalities are aggregated into 26 LLMSs, two of which (Agerola and Torre Annunziata) have their centroid municipality i.e. the gravitational pole for the cluster of the municipalities belonging to the system - located in the province of Naples, and they also comprise municipalities in both the provinces of Salerno and Naples. 


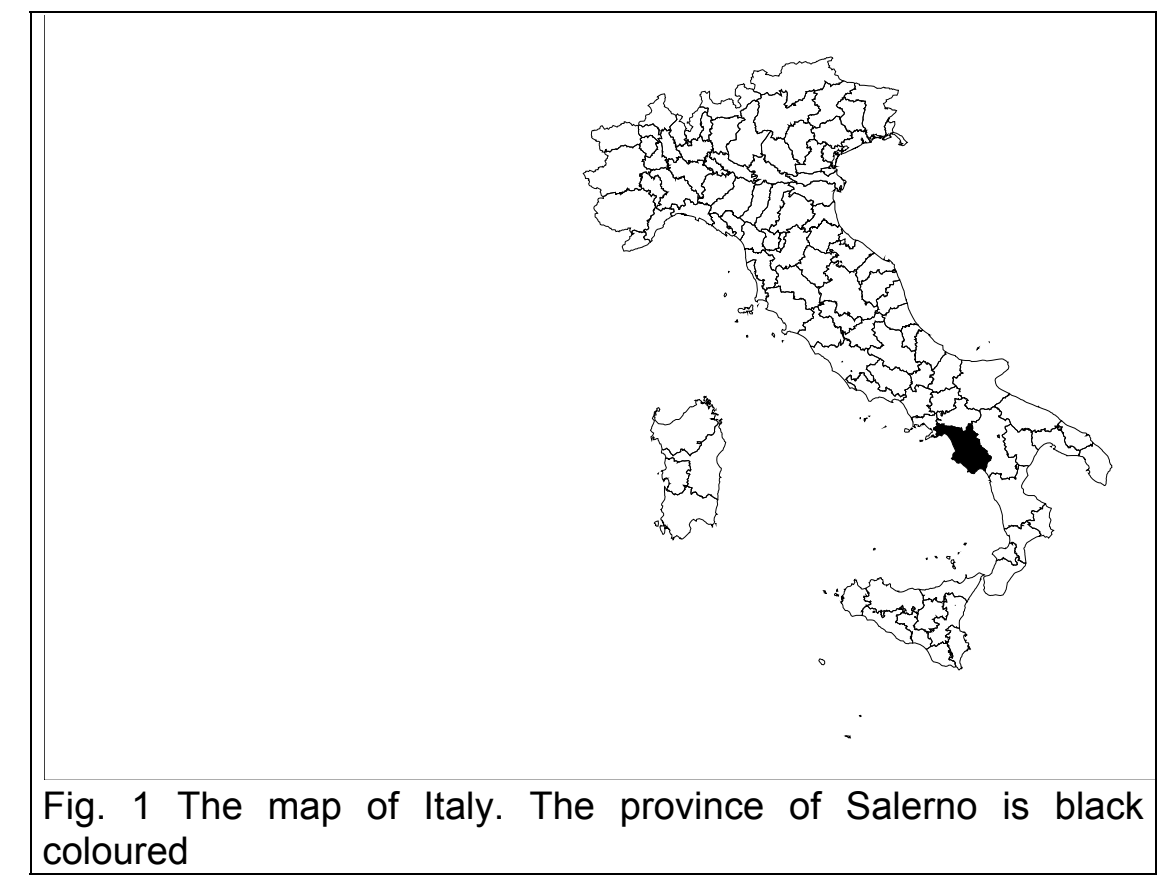

As in the rest of the Mezzogiorno, the average territorial size of the LLMS in the Province of Salerno is smaller than the national average. This feature is mainly due to the differing infrastructure endowments of the north and south of Italy. The largest LLMS (Sala Consilina, $719 \mathrm{sq} \mathrm{km}$, or $14.6 \%$ of the province's surface area) has developed along the motorway between Salerno and Reggio Calabria, although it has only 64,830 inhabitants, or $5.9 \%$ of the province's total population. The LLMS of the provincial capital, the city of Salerno, is the largest in terms of population $(294,220$ inhabitants) and the third largest in terms of geographical size. This LLMS can be considered to be the metropolitan area of the province, given that it is the main geographical pole of the latter and that 15 municipalities in the metropolitan area gravitate towards it. The second LLMS in terms of population is the area of Nocera Inferiore, which comprises $10.6 \%$ of the province's total population and has the highest demographic density (1765 inhabitants per square kilometre). 
Another important local system is that of Battipaglia, which, having grown apace in recent decades, today has a total population of around 115 thousand inhabitants. The smallest LLMSs are those located along the Amalfitana coastal belt (Maiori, Positano and Amalfi) and on the Cilento coast (Castellabate and Pollica). To be noted is that almost all the LLMSs whose centroid municipalities are located on the coast have developed inland, which indicates the presence of commuter movements from the inland municipalities to those on the coast. In other words, the inland municipalities gravitate towards the coast, which has undergone greater development and more sustained population growth, and offers a wider range of services.

\subsection{The LLMS specialization indexes}

Calculated for each LLMS in the province of Salerno were the index and manufacturing specialization, and the specialization indexes by economic grouping of manufacturing activities. The LLMSs can be divided into three groups: (i) those with specialization indexes greater than 1; (ii) those with specialization indexes less than 1 but above the average for the Campania region; (ii) those with specialization indexes below the average for Campania.

Only three LLMSs had specialization indexes above the national average: Agerola, Battipaglia and Nocera Inferiore. Agerola is a relatively small LLMS with only 352 employees in the manufacturing sector, and it specializes in dairy products. The second LLMS in terms of manufacturing specialization is Battipaglia, in which a number of petrochemicals and engineering companies are located. The former industry, which includes firms producing rubber, plastic and insulated cable and wire, is more important in terms of its specialization index; but the latter is more important in terms of employment. Unlike the other LLMSs, Battipaglia has industries which may be called 'non-natural' in that they are not directly related to the area's endowment of natural resources. The presence of petrochemicals and engineering plants 
in this municipality dates back to the 1970s, when a popular insurrection provoked by closure of a tobacco factory and a sugar factory in Battipaglia forced the government to locate chemicals and engineering companies in the town to defuse the tension. It should be stressed, moreover, that Battipaglia is one of those areas in Italy which have undergone exponential population growth. Nocera Inferiore, which is the most important LLMS in terms of employment in manufacturing (8849 workers), specializes in the processing and conserving of fruit and vegetables (tomatoes). A number of engineering companies are also located in the area: radio telephony and metal products. The latter sector is in part a branch of the agro-food sector. Nocera Inferiore is one of the eight industrial districts singled out by the Campania Regional Government.

The second group of LLMSs have specialization indexes which are less than 1 but higher than the average for Campania.

The majority of these LLMSs are located along two major roadways which lead southwards from Salerno. The first follows the coastline while the second extends down to the Buccino LLMS.

The LLMSs with low specialization indexes (below both the national average and that of Campania) are mainly specialized in food and furniture. They can be further divided into 


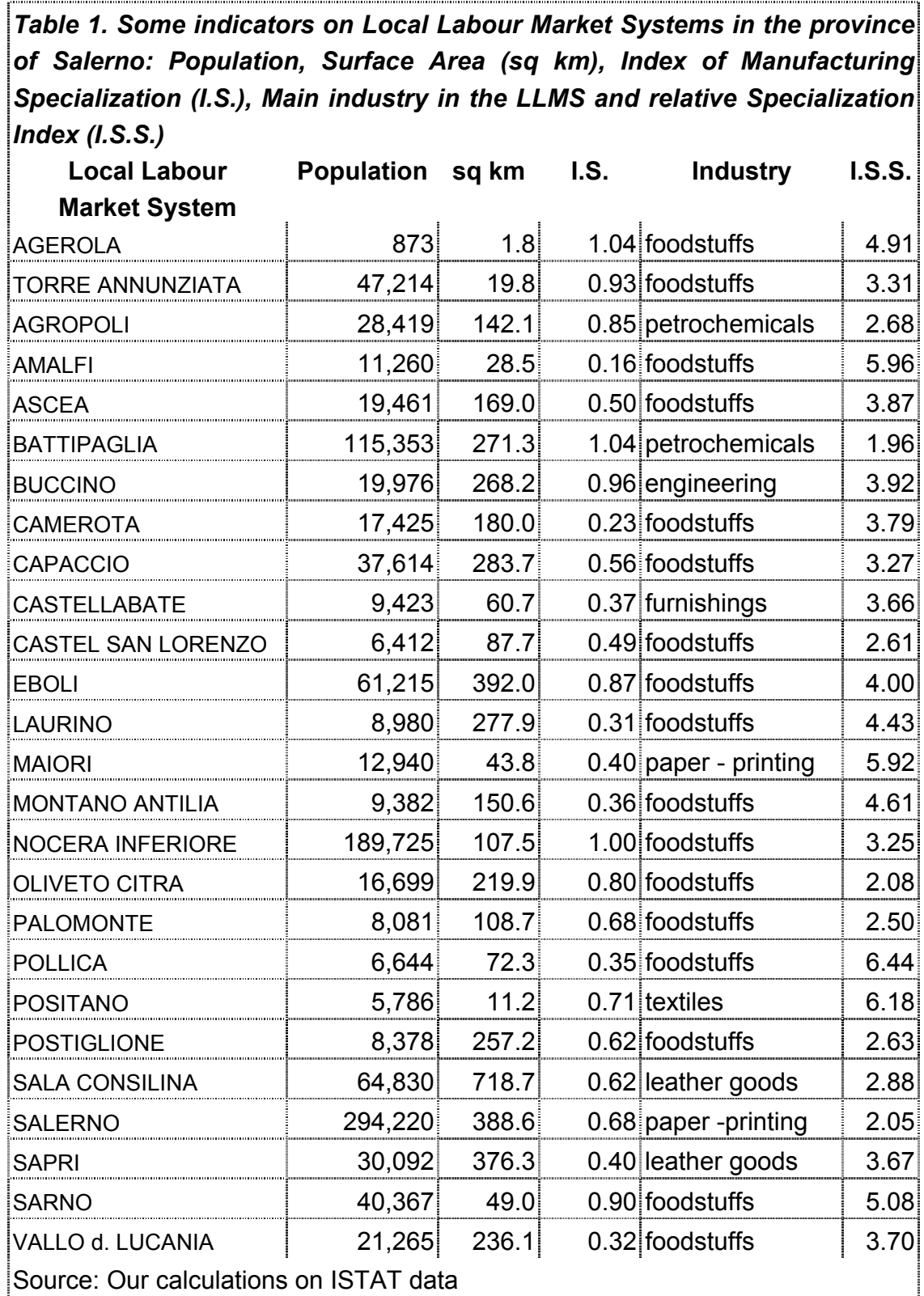


two sub-groups. The first of these sub-groups comprises the coastal LLMSs specialized in consumer services, and especially in food production, with the exception of Positano (textiles), Maiori (traditional paper manufacture) and Castellabate (wood and carpentry). They produce traditional foodstuffs for the local tourist industry. The second sub-group comprises the LLMSs located inland from the coast. These systems have relatively high specialization indexes in food and furnishings, or in manufacturing activities engaged in producing goods for sale locally to satisfy basic needs (food and housing). Exceptions are Sapri and Sala Consilina, which have low levels of manufacturing specialization but a different productive structure due to the presence of the leather goods industry. The Salerno LLMS is specialized in services.

The specialization indexes can be read in a different way. The inland area of Cilento comprises LLMSs despecialized in manufacturing but specialized in food and furnishings, and whose production is geared to satisfying local demand. Located towards the coast are activities supporting the tourist industry (food and traditional local sectors), while lying inland are LLMSs specialized in light industry and located along the motorway.

2.3 Micro Areas (groups of municipalities) specialized in manufacturing. A cluster analysis ${ }^{2}$

After analysing the characteristics of LLMSs, we narrowed the focus of analysis by conducting cluster analysis on the levels of productive specialization of individual municipalities, the purpose being to verify the existence of proto-industrial (or pre-industrial) districts in the province. The aim was to identify groups of municipalities in individual local systems with indexes of

\footnotetext{
${ }^{2}$ More detailed results of this cluster analysis are reported in G. Coppola., la struttura produttiva della provincia di Salerno. Working Paper 35.01 Dipartimento di Scienze Economiche e Statistiche dell'Università degli studi di Salerno.
} 
manufacturing specialization which, although high, were not sufficiently high to qualify them as specialized in manufacturing. In other words, our intention was to identify those homogeneous areas of manufacturing specialization within the LLMSs which did not emerge when the local system as a whole was considered because they were not of sufficient weight to influence the levels of specialization of larger geographical areas. The intentions was also to determine, if possible, the factors responsible for the existence of such areas.

The statistical method used was cluster analysis of 27 indicators calculated for each municipality. These indicators were the following:

- Manufacturing Specialization Index [(manufacturing workforce/total workforce)/ITALY ${ }^{3}$ ];

- Index of Manufacturing Business Density [(number of local manufacturing enterprises/resident population)/ITALY];

- Manufacturing Structure Complexity Indicator [number of types of manufacturing activity - 1991 ATECO, Section D - set in ratio to the provincial maximum];

- Relative weight of micro firms [(number of workers in local manufacturing enterprises with up to 9 employees/total workers)/ITALY]:

- 22 specialization indexes for each of the divisions of subsection D of the 1991 ATECO Classification. Only those existing in the province were considered.

The first two indexes were also included in order to reflect the provisions of the Ministerial Decree of 21 April 1993, which takes these indicators to be the two main parameters for definition of an industrial district.

The Manufacturing Structure Complexity Indicator (MSCl) was included to distinguish municipalities with more complex productive structures from those with simpler ones. The underlying reason for its inclusion was that account could thus be taken of the size of a municipality's productive structure.

\footnotetext{
${ }^{3}$ For the sake of brevity, 'ITALY' denotes the analogous ratio calculated for the country as a whole.
} 
The weight of small firms was divided into two indexes: microfirms with up to 9 employees, and small firms (from 10 to 49 workers). Micro-firms were considered separately from small firms because they have considerable economic importance in the Mezzogiorno.

The cluster analysis produced two partitions: 3 large groups of municipalities were identified by the first, and 9 smaller groups by the second. The former 3 groups sharply distinguished municipalities despecialized in the manufacturing sector from those with specialization indexes above the regional (and also provincial) average, and from those with very high manufacturing specialization indexes (plastics). The 3 groups in the first cluster were:

- Cluster 1/3. 90 municipalities. Municipalities despecialized in manufacturing. These are municipalities with specialized micro-firms operating in the wood and food sectors. Located mainly in the southern part of the province, they have basic economies and engage almost exclusively in manufacturing activities to satisfy local demand.

- Cluster 2/3. 2 municipalities. Municipalities specialized in manufacturing with high specialization indexes (2.01). This is an area of small size which will be discussed in detail later.

- Cluster 3/3. 64 municipalities. Municipalities specialized in manufacturing with manufacturing specialization indexes $\mathbf{0 . 8 7}$ points above the average for the region. These municipalities are located in the northern part of the province, and in the south along the Salerno - Reggio Calabria motorway (Figure 1).

The second partition identified 3 groups of municipalities despecialized in manufacturing, 2 clusters of contiguous specialized municipalities (plastics, leather goods), and 4 groups of municipalities with specialization indexes above the average. The following 9 clusters of municipalities were obtained: 


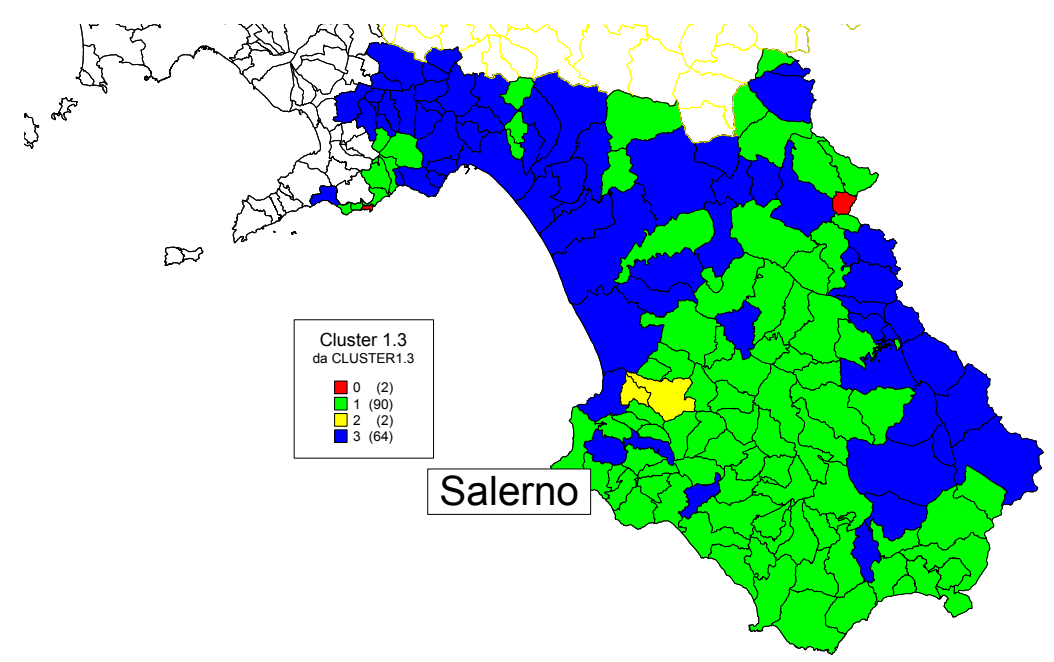

Fig 2. Results of the first cluster analysis. Map of the province of Salerno.

- Cluster 1/9. 45 municipalities. Despecialized municipalities (Manufacturing Specialization Index $(\mathrm{MSI})=0.38$ ). These municipalities are located in mountainous areas of the province with only sporadic wood and iron crafts activities.

- Cluster 2/9. Non-specialized municipalities $(\mathrm{MSI}=0.45)$. This class comprises municipalities situated both inland and on the coast. In the former case these are closed-economy municipalities whose manufacturing activities are geared solely to satisfying the basic needs of the local population (food and housing). In the latter case, the presence of businesses engaged in food production and construction is due to the local tourist industry.

- Cluster 3/9. 4 municipalities. Non-specialized municipalities $(\mathrm{MSI}=0.1)$. These are inland municipalities almost entirely devoid of manufacturing activity.

- Cluster 4/9. 2 municipalities. Municipalities specialized in manufacturing (ISM = 2.1). Located on the edge of the Cilento and Vallo di Diano National Park. this industrialized area is of very small size but displays high specialization indexes. Medium-sized factories sub-contracted to firms in northern Italy produce rubber components for cars. The location of this industry in the area 
results from an enterprise creation programme undertaken in the early 1980 s, which should have covered a larger area but was only in partly implemented.

- Cluster 5/9. 4 municipalities (MSI =0.8). This group comprises four municipalities, two of which (Pagani and Battipaglia) have high specialization indexes in electrical machinery production (DL32). Located in the municipality of Battipaglia are a number of firms specialized in the manufacture of insulated cable and wire. As said, these firms were established in Battipaglia in the first half of the 1970s under a government scheme designed to resolve the employment crisis caused by the closure of a sugar factory and tobacco factory. It was decided at the time to create a 'development pole' by investing in innovative sectors (Carbone, 2000). Situated in the municipality of Pagani - whose specialization index is 16.3 - is an Ericsson Fatme plant which employs around 600 workers. The presence of this firm, too, is the result of political intervention. It should be stressed that both these municipalities have very high population densities.

- Cluster 6/9. 4 municipalities. Leather goods proto-district $(\mathrm{MSI}=1.10)$. These four municipalities are located in the southern part of the province and specialize in footwear. In actual fact, they are small firms which undertake only part of the production process (stitching), largely on commission to shoe manufacturers in the Grossetto area. They make much use of home workers and, in recent years, of immigrant labour as well. This proto-district arose during the mid-1970s, mainly as a result of the links between emigrants returned home from Tuscany with emigrant relatives still living in that region and working in its footwear industry.

- Cluster 7/9. 4 municipalities $(\mathrm{MSI}=0.61)$. This cluster comprises four small municipalities which differ so greatly from each other that it is difficult to identify any shared features. They have simple productive structures, and the firms located within them operate in highly specific sectors, which pushes up the values of some indexes of sectoral specialization. For example, in the municipality of Lustra (in the Cilento region) there is a factory specialized in the manufacture of perfumes for a famous Swiss cosmetics company which was founded by an emigrant on his return from working for the parent company. 
- Cluster 8/9. 44 municipalities $(\mathrm{MSI}=0.9)$. This area has a manufacturing specialization index above the average for the Campania region (0.9). These are municipalities located along the main communication routes, in particular the motorway and the railway. Belonging to this macro-area are municipalities specialized in agro-food products (tomato canning). The majority of them are located in the north of the province (Nocerino-Sarnese), which the Campania Regional Government has defined an industrial district specialized in agro-food production. The factors responsible for the birth of this area of specialization were the fertility of its soil and its proximity to the important outlet market represented by the metropolitan area of Naples. However, the area's food preserving industry dates back to 1882 when Giuseppe Cirio, a native of Piedmont, set up the first tomato canning factory in southern Italy (Bonazzi, Bagnasco, Casillo, 1972). Moreover, an important role in the development of the area's food preserving industry was played by the Green Plans of the 1960s. This area also comprises municipalities specialized in textiles (DB18), like Positano, which is renowned for the Positano Fashion company founded in the early 1960s, as well as textiles sub-suppliers. To be noted is an under-specialization by area: ties are made in one area (Campagna), garments like trousers and swimming costumes in another (Baronissi). These are outlying areas where the cost of labour - which sometimes provides a supplementary household income - is relatively low. In these areas it is easier to decentralize part of the production process to home workers (with the attendant evasion of social security payments because the local sub-supplier only insures one worker, who is helped by the members of his/her family). The use of immigrant workers has recently become widespread.

- Cluster 9/9. Two municipalities specialized in manufacturing and food production. Tobacco factories largely predominate in these two municipalities (Cava dei Tirreni and Scafati). 


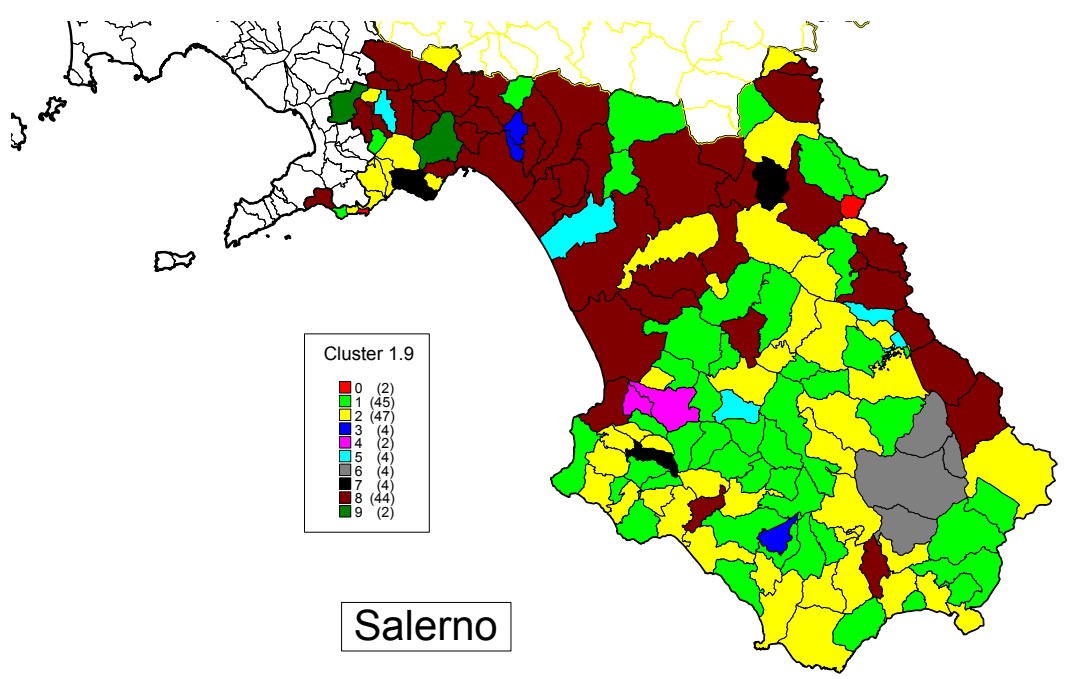

Fig 3. Results of the second cluster analysis. Map of the province of Salerno.

\section{Institutional factors in the specialized areas}

Having determined the specialized micro-areas, we measured those features of each area's institutions and values-systems which should foster the onset of virtuous mechanisms of interaction between productive and social structures (Brusco, Paba, 1997).

For this purpose, as said, we applied a statistical procedure for qualitative variables (simple correspondence analysis) which synthesized the data collected by a questionnaire administered to a sample of enterprises in the province of Salerno. The aim was to cross-reference the clusters identified by the preceding analysis with variables available by the questionnaire, in order to check for the existence in these areas of the institutional factors essential for the growth of industrial districts. 
The correspondence analysis is a statistical technique for analysing categorical data. This method is particularly helpful in analysing cross - tabular data in the form of numerical frequencies. We can distinguee the simple correspondence analysis and the multiple one, in the first only the association amongst the raw and column variables are analysed, in the second also the association between each variables and itself (for more detail see Greenacre, 1993).

\subsection{The data}

The data used for this analysis were collected by an ad hoc survey of a sample (no. 462) of firms, of all sizes, located in the province of Salerno. The questionnaire was structured into nine sections (about 200 questions) covering all aspects of the firm.

The first section, besides general aspects regarding legal form, the number of partners and precise description of the productive activity, included a detailed part on the birth of the firm, which collected details on the founder, variations in legal form, the activity of the firm's owner before setting up the present business, the use of enterprise creation grants, and the occupational status of the owner's father and mother.

The next section dealt with innovation, seeking to specify both the types of innovation introduced in the firm and forms of financing and sources of information.

The third, fourth and fifth sections analysed managerial aspects. It first examined the firm's purchase markets, and therefore gathered information on investments in machinery, the purchase of raw materials and semi-manufactured goods. The origin of these production factors was of particular interest. Another set of questions covered the firm's selling market, also as regards sales performance over the previous three years. The purpose of these questions was to determine the presence of possible production value chains "filiere" , or at least linkages upstream or downstream of the production process. Particular attention was paid to identification of the geographical areas in 
which the firm's markets were located. There followed a section on financial management, on the relationship with banks, and personnel management. These two last sections also yielded abundant information, the aim being to quantify not only aspects of the firm but also their type and territoriality, and in particular where information and production factors were obtained. The part on management concluded with financial information concerning the firm's balance sheet.

The questionnaire continued with two sections on buyers and sub-supply and concluded with a section relative to the social context. This final part asked the respondent for his/her opinions on local facilities and institutions, and on the firm's relations with the local community and with other enterprises in the area (for more details to see Coppola, Farace, Giordano, Mazzotta, 1998).

\subsection{The variables}

Although the debate on the origin of the territorial district still continues and the question is far from being resolved, one of the first aspects to consider is undoubtedly the initial phase of firms' lifetimes. A district may be brought into being by an efficient combination of production factors already present locally, or which can be acquired from the outside, and by the action of one or more 'driving' enterprises. A driving enterprise may already exist or it may arise with the district; it may also be an external or local enterprise. A first channel through which driving enterprises may engender a district is that of spin-offs whereby workers, executives and employees decide to set up on their own, even in competition against their previous employer. It was for this reason that the variable on the firm-owner's previous activity $\left(p^{*}\right)^{4}$ was included in the questionnaire (Table 2).

\footnotetext{
${ }^{4}$ The asterisk denotes all the variables beginning with the letter specified: e.g. $\mathrm{p}^{*}$ $=\mathrm{p} 1, \mathrm{p} 2, \mathrm{p} 3 \ldots \mathrm{pn}$.
} 
A driving enterprise may operate through its suppliers, a channel which was analysed by the questions on the purchase of machinery, raw materials and semi-manufactured goods $\left(q^{*}\right)$.

Also important for the birth of districts is the social context, starting with the family. Kinship and friendship networks in a local community are functional to the accumulation of initial capital and the flexible regulation of the labour market (Paci, 1999). Moreover, kinship should favour a good climate and mutual trust in business dealings, as well as the rapid transmission of information and knowledge (Bagnasco, 1988). It was therefore important to determine whether the enterprise had been handed down from one generation to the next $\left(f^{\star}\right)$.

Essential for the birth and growth of a district is the circulation of technical information on purchase and selling markets, on organizational systems, and on individual and entrepreneurial experiences. This circulation of information among enterprises creates what Marshall called "industrial atmosphere". Included in the questionnaire as a consequence were items on the way in which the enterprise acquired information about the machinery to use $\left(c^{*}\right)$ and financial facilities $\left(d^{*}\right)$.

More recently, much emphasis has been placed on the importance of the local institutions and infrastructures in fostering an area's development. Accordingly, in order to ascertain their efficiency, the respondents were asked to express their opinions about local infrastructures and institutions $\left(0^{*}=\right.$ efficient, $d^{*}=$ inefficient, $i^{*}=$ neither).

Then examined were selling markets (sale of semimanufactured articles $\mathrm{v}^{*}$ and final products $\mathrm{vf}^{*}$ ), given that it is widely acknowledged that firms must create 'long networks' and go beyond local boundaries, even extending their markets into foreign countries.

Finally, the dynamism of the area was assessed by a set of questions on the firm's use of credit or self-financing $\left(i a^{*}-i b^{*}-i c^{*}-\right.$ $\left.i^{*}\right)$. 
Table 2 Variables considered in the simple correspondence analysis

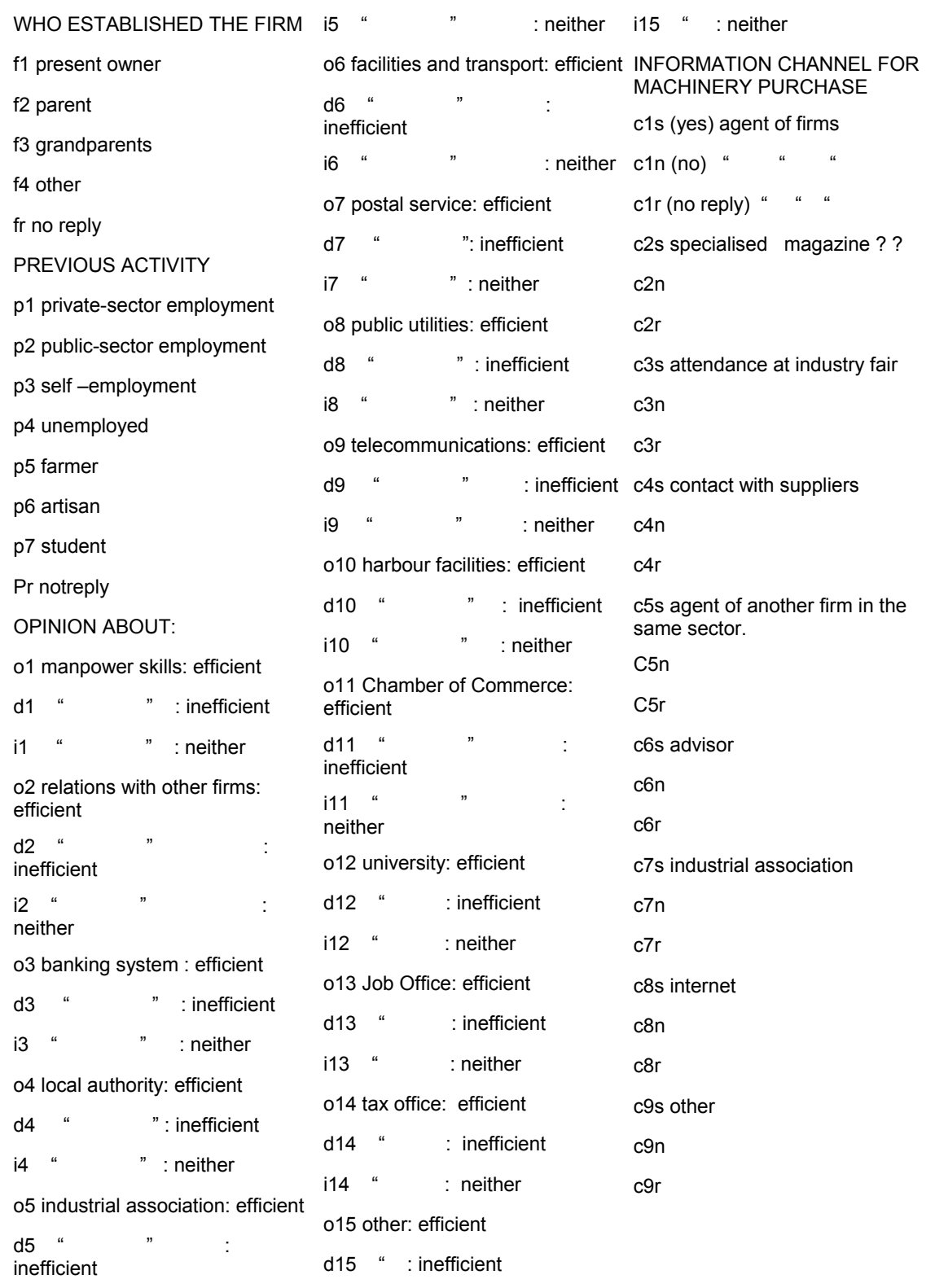


Table 2 Variables considered in the simple correspondence analysis (continua)

\begin{tabular}{|c|c|c|}
\hline INFORMATION CHANNEL FOR & q2 Campania & Self financing \\
\hline d1s (yes) professional & q3 South & ia1 $10-25$. \\
\hline accountant/consultant & q4 Centre - North & ia2 $25-50$ \\
\hline d1n (no) “ & q5 foreign & ia3 $50-75$ \\
\hline d1r (no reply.) & q6 Equally distributed & ia4 >75 \\
\hline $\begin{array}{l}\text { d2s Official source (G.U. - } \\
\text { B.U.R.C.) }\end{array}$ & Qr No reply & Iar No reply \\
\hline$d 2 n$ & $\begin{array}{l}\text { RAW MATERIALS: AREA OF } \\
\text { ORIGIN AREA }\end{array}$ & Ordinary credit \\
\hline $\mathrm{d} 2 \mathrm{r}$ & Qm1 Salerno & \\
\hline d3s Mass media & qm2 Campania & Ib2 \\
\hline$d 3 n$ & qm3 South & ib3 \\
\hline$d 3 r$ & qm4 Centre - North & ib4 \\
\hline d4s Industrial association & qm5 Foreign & $\mathrm{Ibr}$ \\
\hline$d 4 n$ & qm6 Equally distributed & Facilitated credit \\
\hline$d 4 r$ & Qmr No reply & ic1 \\
\hline $\begin{array}{l}\text { d5s internet } \\
\text { d5n }\end{array}$ & $\begin{array}{l}\text { SEMI-MANUFACTUREDS: } \\
\text { AREA OF ORIGIN }\end{array}$ & $\begin{array}{l}\text { ic2 } \\
\text { ic3 }\end{array}$ \\
\hline$d 5 r$ & qs1 Salerno & ic4 \\
\hline d6s occasional way & qs2 Campania & Icr \\
\hline d6n & qs3 South & Without security \\
\hline$d 6 r$ & qs4 Centre - North & id1 $10-25$ \\
\hline d7s Chamber of Commerce & qs5 Foreign & id2 $25-50$ \\
\hline$(\mathrm{CCIAA})$ & qs6 Equally distributed & id4 >75 \\
\hline d7n & Qsr No reply & Idr No reply \\
\hline $\begin{array}{l}\text { d7r } \\
\text { d9s other }\end{array}$ & $\begin{array}{l}\text { SEMI-MANUFACTUREDS: SALE } \\
\text { AREA. }\end{array}$ & FINAL PRODUCTS: SALE AREA \\
\hline d9n & v1 Salerno & vf1 Salerno \\
\hline$d 9 r$ & v2 Campania & vf2 Campania \\
\hline & v3 South & vf3 South \\
\hline from the area & v4 Centro - Nord & vf4 Centre - North \\
\hline As (yes) & v5 Foreign & vf5 Foreign \\
\hline An (not) & v6 Equally distributed & vf6 Equally distributed \\
\hline $\operatorname{Ar}$ (no reply.) & Vn Not relevant & Vfn Not relevantt \\
\hline Machinery: area of origin & Vr No reply & Vfr No reply \\
\hline q1 Salerno & COVERING INVESTMENT & \\
\hline
\end{tabular}




\section{$4 \quad$ Correspondence analysis: results}

The first step was to explore the three groups of municipalities (Clusters 1/3, 2/3 and 3/3) singled out by the previous analysis. Note that these three clusters (Table $3 a$ in the appendix) differed from each other in qualitative terms as well. In fact, whilst cluster $2 / 3$ (municipalities specialized in manufacturing) was negatively correlated with the first dimension, clusters $1 / 3$ (municipalities not specialized in manufacturing) and $3 / 3$ (municipalities specialized in manufacturing) were correlated with the second dimension, the former negatively and the latter positively.

Analysis of cluster $2 / 3$ (a2, Table $3 a$ in the appendix), which covered a very small area (only 2 municipalities) which comprises enterprises producing rubber car components on sub-contract (Figure 1.A) confirms the relatively recent origin of this productive activity: in fact, there was no evidence of a tradition handed down from previous generations. Nor did we find evidence of 'budding', that is, the rise of skilled workers to the status of entrepreneurs, as shown by the negative relationship with the variable $\left(\mathrm{p} 1^{5}\right.$, Table $3 a$ in the appendix), from which one deduces that the firm's owner was previously a manual worker in a firm belonging to the same sector or a different one. In fact, more apparent here is the process of 'competitive imitation' which fosters the birth of new entrepreneurs, alone or more frequently in partnership, sometimes with friends. This results from the negative relationship with variables (f1 and f3), which attributed the founding of the enterprise to the owner alone or to previous generations, and the positive relationship with variable (f4), which attributed it mainly to entrepreneurial groups with no kinship relations.

\footnotetext{
${ }^{5}$ Considered as significant were the variables with a COR (the percentage of the variable's contribution to inertia explained by each dimension) greater than the total inertia explained by each dimension. For example, considered significant for the first dimension in the first analysis were variables with a COR $>78.31 \%$. CTR is the contribution of each variable to explanation of the inertia, CORR = coordinate on the axes.
} 
Also of great interest are the variables relating to the local institutions. The questionnaire included a set of questions on the respondent's opinion of certain institutions and infrastructures.

These were predominantly viewed as inefficient, with the exception of harbour facilities and the Chamber of Commerce, which operated a twice-weekly advice bureau serving the Cilento area.

As regards investments, one notes a certain stagnation in this area, given that, for the first dimension, the variables on how information was obtained about machinery to purchase $\left(c 1^{*}-\mathrm{c} 9^{*}\right)$ were not significant, while "no reply" was the most frequent response to the question about the existence of financing on favourable terms $\left(\mathrm{d} 1^{*}-\mathrm{d} 9^{*}\right)$. This stagnation was also evidenced by the lack of significance of the variables relating to forms of investment financing, and therefore the scant use of credit, facilitated or otherwise $\left(\mathrm{i}^{\star}\right)$.

Moving to the second dimension, to be noted is that the positively correlated variables, and therefore those that most characterize cluster $3 / 3$ (a3, Table $3 a$ in the appendix, specialized cluster, Figure $1 \mathrm{~A}$ ), again evidence the relatively young age of firms founded directly by proprietors (f1) who had started from the situation of student (p7), unemployed (p4) or agricultural entrepreneur ( $p 5$ ) to set up a manufacturing business. This had been made possible by such advantageous features as a skilled workforce (o1), good relations with other firms (o2) and with the job placement offices (013). To these can be added the efficient functioning of the trade associations and the Chamber of Commerce, which disseminated information about the availability of facilitated financing ( $d 4 \mathrm{~s}$ and $\mathrm{d} 7 \mathrm{~s}$ ). Nevertheless, some of the firms surveyed only found out about such financing by chance (d6s).

The importance of relations with other firms is also evidenced by the positive relationship with the variables identifying relationships with purchaser enterprises and the agents of supplier firms (c4s) as the source of information on the fixed assets to purchase (c1s). These results are also indicative of dependence on supplier firms and buyers.

The enterprises in cluster $3 / 3$ worked mainly on sub-contracts. 
This explains the positive relationship with the variables on the sale of semi-finished goods $\left(\mathrm{v}^{*}\right)$, which indicated the predominance of both the local market and the one extending beyond the boundaries of the southern area to the Centre-North of Italy and abroad. By contrast, the variables on the sale of finished products were not significant $\left(\mathrm{vf}^{\star}\right)$.

Regarding the variables relative to forms of financing, there was a strong positive relationship with self-financing (ia*) and with facilitated credit or non-repayable loans $\left(\mathrm{ic}^{*}-\mathrm{id}^{*}\right.$ ). Although these results highlight dependence on purchaser firms and suppliers, they are also indicative of dynamism in terms of investments.

We finally turn to cluster $1 / 3$ (a1, Table $3 a$ in the appendix, non-specialized cluster, Figure $1 \mathrm{~A}$ ), which is negatively correlated with the variables that we saw characterizing cluster $3 / 3$. To be noted is that entrepreneurial activity in this area is more of a family tradition, considering that variable on parents as founders of the business (f2) assumes importance. Moreover, all the owners of these firms had been engaged in entrepreneurial activity (also as self-employed professionals) before they set up their present businesses.

With regard to the role of the institutions, the banking system and the transport system were found to be the main strengths of the area (03 - 06). Skilled labour is not of significance, even though firms prefer to hire local workers, but more for practical reasons (because travel to work is more easier) than because they are particularly well qualified (as). The firms in cluster $1 / 3$ obtain their supplies mainly from enterprises in the Salerno and Campania region $\left(\mathrm{q}^{*}\right)$; and they sell the majority of their products to firms and households in the area, or at most in the Mezzogiorno $\left(v^{*}\right)$.

Although the foregoing analysis yielded a large amount of information, it was restricted by the fact that clusters $1 / 3$ and $3 / 3$ covered an extremely broad area comprising small ones which should have been considered separately. It was for this reason that we singled out the nine clusters, which are now discussed.

Two significant dimensions also emerge when 9 rather than 3 clusters are considered. In fact, by following the practical rule of selecting dimensions up to the value $1 / Q$, which denotes the inertia 
and the percentage of inertia explained by the dimensions (where $Q$ is the number of variables considered, in our more than $100-$ less than $1 / 100=0.01$ ), and by inspecting Table $3(b)$, we could consider all dimensions.

Table 3. Correspondence analysis: inertia and percentage of inertia

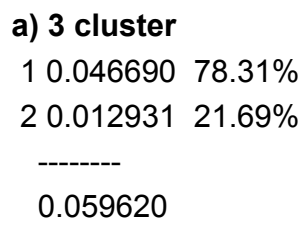

0.131696

Once again, the first dimension concerns the small specialized area consisting of only two municipalities (cluster 4/9, b4 in Table $3 b$ in the appendix, Figure 1B), and located in which are subcontractor firms producing rubber gaskets for cars. Analysis confirms the absence of traditional family firms, and the predominance of recently-founded businesses. It also shows the weakness of local infrastructures and institutions, except for the Chamber of Commerce, and highlights even more clearly the stagnation of the sector, which works on sub-supply without undertaking investments, producing a tried and tested product using raw materials purchased from firms in the Centre-North.

On moving to the second dimension, we find a positive relationship with cluster $8 / 9$ (b8, Table $3 b$ in the appendix, 
specialized cluster, brown area in Figure 1B) and a negative one with cluster 2/9 (b2, non-specialized but primarily food, yellow area). Consideration of the row variables shows that the brown cluster largely consists of enterprises directly founded by the present owner (f1), so that a strong relationship (or dependence) emerges with supplier enterprises, which are also the main sources of information $\left(\mathrm{c}^{*}\right)$ about capital assets to be purchased, albeit in a context of scant investment indicated by the nonsignificance of the relative variables $\left(q^{*}\right)$. This finding, together with the others given below, shows that there are firms in this area which work on their own account (food) and others on subcontracts (textiles). The former are stagnant, while the latter are, in a certain sense, stimulated by purchasers to undertake investment in new machinery. There is no preference for local manpower $\left(a^{*}\right)$, probably because these firms are not engaged in traditional production activities which require specialized workers. Raw materials are mainly purchased abroad (qm5), whilst semi-finished goods, although they do not originate in the Salerno area, come from the southern regions $\left(q s^{*}\right)$. Sales $\left(v^{*}-v f^{*}\right)$ principally concern final products sold either to households or local enterprises. Only a small minority of the firms surveyed marketed their products abroad.

According to the technique of the statistical method, variables positively correlated with cluster $8 / 9$ will be negatively correlated with the yellow cluster 2/9 (non-specialized but mainly food), so that the family structure is even less influential (f4), with a predominance of students or professionals prompted to set up a new business by the efficiency of the Chamber of Commerce (011) and the skilled labour available in the area (as). Machinery was purchased in the Centre-North (q4), raw materials in the South (qm3), and semi-finished goods in the province of Salerno (qs1). Investment (ia*) was covered by self-financing $(25-50 \%)$ but also by facilitated credit (ic* $50-75 \%$ ).

The third dimension correlates positively with clusters 1/9 (b1, Table $3 b$ in the appendix, non-specialized area with a prevalence of wood and metal products, Figure 1B) and 9/9 (b9, specialized area with an important concentration of tobacco processing, Figure $1 \mathrm{~B}$ ), and negatively with cluster $5 / 9$ (b5, area of exogenous 
intervention). Clusters $1 / 9$ and 9/9 can be defined as 'traditional', although the former is non-specialized. Among the row variables which positively explain the first dimension is the recent origin of firms whose owners were previously students or unemployed $\left(p^{*}\right)$. Manpower, relations with other enterprises in the area, and the trade associations are sources of weakness, although tax services (014) and law enforcement agencies (015) are efficient. Information is mainly obtained by attending trade fairs (c3s) and consulting professionals (c6s). The purchase of machinery, raw materials and semi-manufactured articles, when not equally distributed, takes place within the region $\left(\mathrm{qm}^{*}\right)$ or in the CentreNorth (qs*). Both semi-finished and final products are mainly sold on the regional market $\left(v^{*}-v f^{*}\right)$. A medium level of recourse is made to facilitated financing (ic* and id ${ }^{*}$ ).

Efficient for cluster 5/9, which we may call 'advanced manufacturing', were relations with other enterprises in the area, telecommunications, and university instruction. No other distinctive features were apparent, except for the purchase of machinery and raw materials in foreign countries $\left(\mathrm{q}^{*}-\mathrm{qm}^{*}\right)$, and the sale of final products in the local market (vf1).

Finally, the fourth and seventh dimensions respectively correlated with cluster 6/9 (specialized in leather goods) and cluster $7 / 9$ (non-specialized). Characteristic of the former was entrepreneurial activity by family tradition (f2 and $\mathrm{f} 3$ ) and the importance of skilled local manpower. Also significant was trust in the local institutions, in the trade associations, in the job placement system and the tax authorities, although distrust was shown towards banks and advisors. Self-financing amounted to $50-75 \%$, while little use was made of the ordinary credit, and up to $50 \%$ of facilitated credit. Sales mainly concerned final products in the Centre-North.

Cluster 7/9 displayed very few distinctive features apart from a dependence on ordinary credit, and therefore the weight of financial liabilities for firms included in this cluster (ib4). 


\section{Conclusions}

According to the updating literature on development economics, this research presents a construction of a detailed place/sector matrix of the Province of Salerno obtained first by means of statistical analysis of the specialization indexes of the local labour market systems, and then by cluster analysis applied to a set of variables relating to the manufacturing structure of the municipalities in the province of Salerno. Subsequent analysis brought out the variety of specializations in the areas surveyed.

Still evident was the difference between inland areas and the coastal belt constantly pointed out in the literature on the Mezzogiorno. However, inland areas no longer seem to constitute a monolithic phenomenon, given that they display different paths of development. One of the main factors influencing the industrialization indexes of local labour market systems is the presence of communication routes, mainly motorways - besides the physical features of the terrain, of course. More detailed analysis of the municipal indicators led to identification of a number of micro-areas of specialization: clusters of municipalities specialized in leather goods (Buonabitacolo), in textiles (the manufacture of ties), and in light industry. There were then other areas specialized in non-traditional sectors (car components, cables), for which induced investment was of decisive importance.

The feature shared by the majority of these areas was that they comprised firms working on sub-contract, located mainly inland but along major highways. We deduced from the results of the correspondence analysis that there were no true industrial districts in the province, given that there was no evidence of competition/cooperation among enterprises in the same productive sector, nor of networking among firms, institutions and individuals located in a particular area. In fact, of the clusters identified, the one which displayed some of the features of an industrial district was 6/9, in which local labour and trust in the institutions were important. But lacking in this case, too, were close relations among firms and the cooperation which enables the circulation of 
information and the creation or improvement of the external economies vital for an industrial district. 


\section{References}

Bagnasco A. (1988) "La costruzione sociale del mercato." Studi sullo sviluppo di piccola impresa in Italia, II Mulino, Bologna.

Balloni, V. (2000), "Le piccole e medie imprese in Italia: dove nascono, perché nascono e come crescono, L'Industria, 2 , pp 219-236.

Barca, F., Magnani, M., (1989) L'industria fra capitale e lavoro, Bologna, II Mulino.

Bardhan, P., (2000) "Understanding Underdevelopment: Challenges For Institutional Economics From Poor Countries Perspectives", DSE, Workshop Series.

Becattini, G., Bellandi, M., Dei Ottati, G., Sforzi, F. (a.c.) (2001), II caleidoscopio dello sviluppo locale, Torino, Rosenberg \& Sellier, 2001.

Brusco, S., Paba, S., (1997) "Per una storia dei distretti industriali italiani dal secondo dopoguerra agli anni novanta" in Barca F., (a c.), Storia del capitalismo italiano dal dopoguerra a oggi, Roma, Donzelli, 1997.

Ciccone, A., Matsuyama, K.,(1996) "Start-up Costs and Pecuniary Externalities As Barriers To Economic Development", Journal of Development Economics, 49, pp 33-59.

Coppola G. La struttura produttiva della provincia di Salerno. (2001) Working paper n 35.01, Dipartimento di Scienze Economiche e Statistiche. Università degli studi di Salerno.

Coppola, G. Farace S., Giordano F., Mazzotta F. (1999) "Industrial District in the South of Italy AREA (LLMA): Method and First results". Proceedings International Council of Small Business. Naples, June.

Gallup, J.L., Sachs, J.D., Mellinger, A.D.,(1998) "Geography and Economic Development”, NBER, Working Paper 6849, 1998. 
Greenacre M., (1993) Correspondence Analysis in Practice, Academic Press Limited, London.

Krugman, P. (1991), "History versus Expectations", The Quarterly Journal of Economics, May, pp 651-667.

Matsuyama, K., (1991) "Increasing Returns, Industrialisation and Indeterminacy of Equilibria", Quarterly Journal of Economics, 106, pp 617-650.

North, D.C., (1991) "Institutions", Journal of Economic Perspectives, 5(1), pp 97-112,.

Paci, M., (1999) Alle origini dell'imprenditorialità e della fiducia interpersonale nelle aree ad economia diffusa, in Gruppo di Ancona.

Ray, D., (1998) Development Economics, Princeton, University Press.

Rodrick, D., (2000) "Institutions For High-Quality Growth: What They Are and How To Acquire Them", NBER, Working Paper 7540, .

Rodrick, D., Hausmann, R., (2002) "Economic Development As Self-Discovery", NBER, Working Paper 8952,

Signorini, L.F., (a.c.) (2000), Lo sviluppo locale, Roma, Donzelli.

Viesti G. (2000) Come nascono i distretti industriali, Bari, Laterza 


\section{Appendix}

Table. 3a Correspondence analysis: row and column contributions - 3 clusters

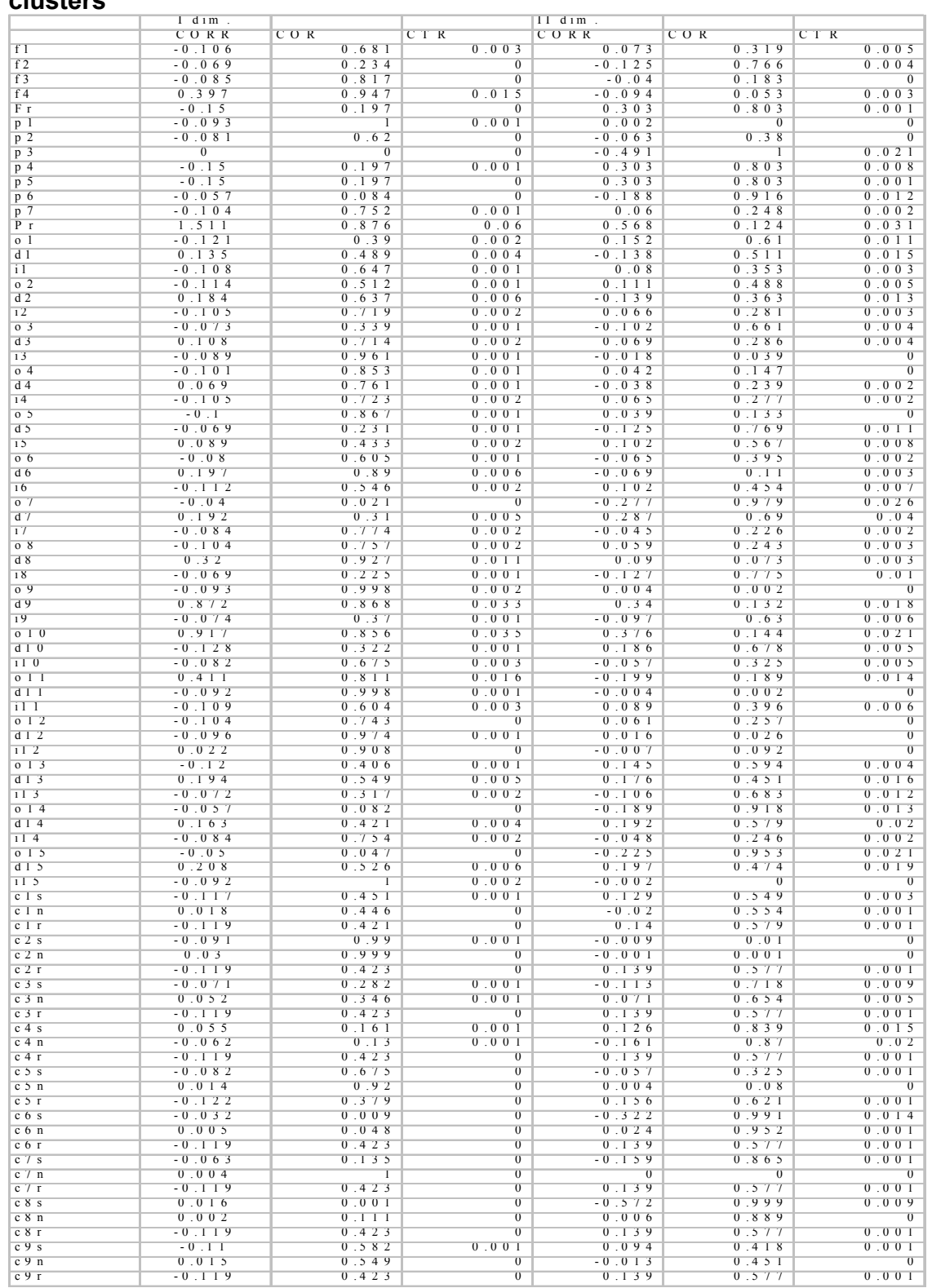


Table. 3a Correspondence analysis: row and column contributions - 3 clusters (continua)

\begin{tabular}{|c|c|c|c|c|c|c|}
\hline & l dim. & & & $11 \mathrm{~d} 1 \mathrm{~m}$ & & \\
\hline & CORR & $\mathrm{COR}$ & C T R & CORR & $\mathrm{COR}$ & $\mathrm{CTR}$ \\
\hline d1s & -0.099 & 0.892 & 0.003 & 0.053 & 0.108 & 0.001 \\
\hline $\mathrm{d} 1 \mathrm{n}$ & -0.081 & 0.646 & 0.001 & -0.06 & 0.354 & 0.002 \\
\hline $\mathrm{d} 1 \mathrm{r}$ & 1.573 & & 0.067 & -0.008 & & \\
\hline $\mathrm{d} 2 \mathrm{~s}$ & -0.057 & 0.086 & & -0.186 & 0.914 & 0.005 \\
\hline $\mathrm{d}<\mathrm{n}$ & -0.096 & 0.965 & 0.004 & 0.018 & 0.035 & 0.001 \\
\hline $\mathrm{d}<\mathrm{r}$ & $1.5 / 1$ & & 0.001 & -0.014 & & \\
\hline d $3 \mathrm{~s}$ & -0.098 & 0.912 & 0.001 & 0.031 & 0.088 & 0 \\
\hline d $3 n$ & -0.092 & 0.998 & 0.003 & -0.005 & 0.002 & \\
\hline $\mathrm{d} s \mathrm{r}$ & $1.0 / 1$ & & 0.001 & -0.014 & & \\
\hline d4s $\mathrm{s}$ & -0.120 & 0.321 & 0.001 & 0.11 & 0.649 & 0.005 \\
\hline $\mathrm{d} 4 \mathrm{n}$ & -0.089 & 0.959 & 0.003 & -0.018 & 0.041 & 0.001 \\
\hline $\mathrm{d} 4 \mathrm{r}$ & 1.571 & & 0.067 & -0.014 & & \\
\hline d5s & -0.107 & 0.668 & 0 & 0.075 & 0.332 & \\
\hline$d s n$ & -0.092 & 1 & 0.004 & -0.001 & 0 & \\
\hline$d>r$ & $1.5 / 1$ & 1 & 0.061 & -0.014 & 0 & \\
\hline $\mathrm{d} 6 \mathrm{~s}$ & -0.126 & 0.341 & 0.001 & 0.175 & 0.659 & 0.007 \\
\hline $\mathrm{d} 6 \mathrm{n}$ & -0.088 & 0.915 & 0.003 & -0.027 & 0.085 & 0.001 \\
\hline $\mathrm{d} 6 \mathrm{r}$ & $1.5 / 1$ & & 0.001 & -0.014 & & \\
\hline d7 $\mathrm{s}$ & -0.15 & 0.197 & & 0.303 & 0.803 & 0.005 \\
\hline d7 $n$ & -0.091 & 0.988 & 0.004 & -0.01 & 0.012 & \\
\hline d $7 \mathrm{r}$ & 1.571 & & 0.067 & -0.014 & & \\
\hline d9 $\mathrm{s}$ & -0.023 & 0.004 & & -0.369 & 0.996 & 0.041 \\
\hline dyn & -0.109 & 0.020 & 0.004 & 0.084 & 0.515 & 0.01 \\
\hline d9 $\mathrm{r}$ & 1.571 & & 0.067 & -0.014 & & \\
\hline As & 0.167 & 0.681 & 0.005 & -0.114 & 0.319 & 0.009 \\
\hline $\mathrm{An}$ & -0.122 & 0.383 & 0.004 & 0.155 & 0.617 & 0.024 \\
\hline Ar & 0.079 & 0.008 & & -0.900 & 0.992 & 0.068 \\
\hline q1 & -0.074 & 0.357 & 0.001 & -0.099 & 0.643 & 0.004 \\
\hline $\mathrm{q}^{2}$ & -0.15 & 0.197 & 0.001 & 0.303 & 0.803 & 0.012 \\
\hline $\mathrm{q}^{3}$ & -0.077 & 0.474 & & -0.081 & 0.526 & \\
\hline$q^{4}$ & 0.111 & 0.692 & 0.005 & $-0.0 / 8$ & 0.308 & 0.005 \\
\hline q5 & -0.134 & 0.244 & 0.001 & 0.244 & 0.150 & 0.000 \\
\hline q6 & -0.137 & 0.253 & 0.001 & 0.236 & 0.747 & 0.01 \\
\hline Q r & -0.104 & 0.749 & 0 & 0.06 & 0.251 & \\
\hline Q m I & -0.054 & 0.063 & 0 & -0.206 & 0.937 & 0.025 \\
\hline $\mathrm{qm} 2$ & -0.088 & 0.922 & 0.001 & $-0.0<5$ & 0.018 & \\
\hline $\mathrm{qm} 3$ & -0.022 & 0.003 & 0 & -0.375 & 0.997 & 0.014 \\
\hline $\mathrm{qm} 4$ & 0.288 & 0.583 & 0.009 & 0.244 & 0.417 & 0.023 \\
\hline qm s & -0.139 & 0.245 & 0.001 & 0.244 & 0.755 & 0.006 \\
\hline qm 6 & -0.11 & 0.295 & 0.001 & 0.091 & 0.405 & 0.002 \\
\hline Qm r & -0.128 & 0.321 & 0.001 & 0.186 & 0.679 & 0.006 \\
\hline qs 1 & 0.69 & 0.819 & 0.03 & -0.325 & 0.181 & 0.024 \\
\hline q s 2 & -0.054 & 0.066 & 0 & -0.203 & 0.934 & 0.003 \\
\hline $\mathrm{qs3}$ & -0.15 & 0.197 & 0 & 0.303 & 0.803 & 0 \\
\hline qs4 & -0.104 & 0.154 & 0.001 & 0.059 & 0.246 & 0.001 \\
\hline qs & -0.15 & 0.197 & 0 & 0.303 & 0.803 & 0.002 \\
\hline qs6 & 0.004 & & 0 & -0.509 & & 0.005 \\
\hline Q sr & -0.100 & 0.111 & 0.004 & 0.060 & 0.283 & 0.005 \\
\hline V 1 & -0.15 & 0.191 & 0.001 & 0.303 & 0.805 & 0.01 \\
\hline v2 & -0.044 & 0.028 & 0 & -0.258 & 0.972 & 0.004 \\
\hline v3 & 0.011 & & 0 & -0.548 & 1 & 0.004 \\
\hline v 4 & -0.15 & 0.197 & 0 & 0.303 & 0.803 & 0.003 \\
\hline vo & -0.15 & 0.191 & 0 & 0.305 & 0.805 & 0.001 \\
\hline vo & -0.15 & 0.191 & 0 & 0.303 & 0.805 & 0.004 \\
\hline $\mathrm{vn}$ & -0.085 & 0.828 & 0 & -0.039 & 0.172 & \\
\hline $\mathrm{vr}$ & 0.031 & 0.653 & 0 & -0.023 & 0.347 & 0.001 \\
\hline 1a 1 & -0.15 & 0.191 & 0 & 0.303 & 0.805 & 0.002 \\
\hline 1a 2 & -0.118 & 0.441 & 0 & 0.133 & 0.059 & 0.002 \\
\hline 1a 3 & -0.112 & 0.537 & 0 & 0.104 & 0.463 & 0.001 \\
\hline 1. 4 & -0.119 & 0.421 & 0.002 & 0.14 & 0.579 & 0.009 \\
\hline Iar & 0.068 & 0.417 & 0.001 & -0.081 & 0.583 & 0.007 \\
\hline 101 & -0.15 & 0.191 & 0 & 0.503 & 0.805 & 0.001 \\
\hline 162 & -0.018 & 0.002 & 0 & -0.395 & 0.998 & 0.004 \\
\hline 163 & -0.15 & 0.197 & 0 & 0.303 & 0.803 & \\
\hline 164 & 0.164 & 0.014 & 0 & -1.352 & 0.986 & 0.049 \\
\hline $1 \mathrm{br}$ & 0 & & 0 & 0.023 & & 0.001 \\
\hline Ic 1 & -0.1 & 0.197 & 0 & 0.303 & 0.803 & 0.002 \\
\hline 1c 2 & -0. & 0.197 & 0 & 0.303 & 0.803 & 0.005 \\
\hline 1c 3 & -0 & 0.197 & 0 & 0. & 0.803 & 0.001 \\
\hline 1C 4 & -0.15 & 0.191 & 0 & 0.303 & 0.803 & 0.001 \\
\hline ICr & 0.01 & 0.191 & 0 & -0.019 & 0.805 & 0.001 \\
\hline 1d I & -0 & 0.197 & 0 & 0.303 & 0.803 & 0.003 \\
\hline 1d 2 & -0 & 0.197 & 0 & 0.303 & 0.803 & 0.005 \\
\hline 1d 4 & -0 & 0.197 & 0 & 0.303 & 0.803 & 0 \\
\hline $1 \mathrm{dr}$ & 0.008 & 0.191 & 0 & -0.016 & 0.805 & \\
\hline vfl & -0.099 & 0.893 & 0.002 & 0.034 & 0.107 & 0.001 \\
\hline $\mathrm{v}+2$ & -0.085 & 0.833 & 0.001 & -0.038 & 0.167 & \\
\hline $\mathrm{v}+3$ & -0.055 & 0.069 & 0 & -0.201 & 0.931 & 0.003 \\
\hline V 14 & -0.091 & 0.94 & 0 & 0.025 & 0.06 & \\
\hline vis & -0.081 & 0.891 & 0 & -0.03 & 0.109 & 0 \\
\hline $\mathrm{v}+6$ & -0.088 & 0.921 & 0 & -0.026 & 0.079 & \\
\hline $\mathrm{v}$ fn & 2.0 & 0.985 & 0.09 & -0.251 & 0.015 & 0.005 \\
\hline vfr & -0.112 & 0.541 & 0.001 & 0.104 & 0.459 & 0.002 \\
\hline & $1 \mathrm{~d}$ & & & $11 \mathrm{~d} 1 \mathrm{~m}$ & & \\
\hline cluster & $\mathrm{k}=$ & $\mathrm{COR}$ & C T R & $\mathrm{k}=2$ & $\mathrm{COR}$ & $\mathrm{CTR}$ \\
\hline a 1 & 0.105 & 0.084 & 0.022 & -0.347 & 0.916 & 0.883 \\
\hline $\mathrm{a} 2$ & 2.332 & 0.99 & 0.957 & 0.233 & 0.01 & 0.034 \\
\hline a5 & -0.032 & 0.41 & 0.02 & 0.054 & 0.23 & 0.083 \\
\hline
\end{tabular}


Table. $3 b$ Correspondence analysis: row and column contributions - 9

\section{clusters}

\begin{tabular}{|c|c|c|c|c|c|c|c|c|c|c|c|}
\hline & I DIM & & & II DIM & & & III DIM & & & IV DIM & \\
\hline & CORR & $\mathrm{COR}$ & CTR & CORR & $\mathrm{COR}$ & CTR & CORR & $\mathrm{COR}$ & CTR & CORR & COR \\
\hline $\mathrm{fl}$ & -0.026 & 0.016 & 0 & 0.139 & 0.436 & 0.008 & 0.011 & 0.003 & 0 & -0.14 & 0.443 \\
\hline f2 & -0.101 & 0.123 & 0.001 & -0.085 & 0.086 & 0.001 & 0.076 & 0.069 & 0.001 & 0.151 & 0.272 \\
\hline $\mathrm{f} 3$ & -0.296 & 0.208 & 0.003 & -0.134 & 0.042 & 0.001 & -0.029 & 0.002 & 0 & 0.444 & 0.468 \\
\hline f4 & 0.285 & 0.529 & 0.007 & -0.236 & 0.365 & 0.008 & -0.081 & 0.043 & 0.002 & 0.092 & 0.055 \\
\hline $\mathrm{Fr}$ & -0.546 & 0.299 & 0.001 & -0.723 & 0.525 & 0.002 & -0.158 & 0.025 & 0 & 0.125 & 0.016 \\
\hline pl & 0.314 & 0.424 & 0.016 & -0.001 & 0 & 0 & 0.071 & 0.022 & 0.003 & -0.064 & 0.018 \\
\hline p2 & -0.064 & 0.063 & 0 & 0.082 & 0.102 & 0 & -0.066 & 0.067 & 0 & -0.061 & 0.057 \\
\hline p3 & -0.272 & 0.253 & 0.001 & -0.336 & 0.387 & 0.002 & 0.116 & 0.046 & 0 & -0.113 & 0.044 \\
\hline $\mathrm{p} 4$ & 0.115 & 0.037 & & 0.06 & 0.01 & 0 & 0.246 & 0.171 & 0.005 & -0.186 & 0.098 \\
\hline p5 & -0.201 & 0.144 & 0.001 & -0.099 & 0.035 & 0 & 0.031 & 0.003 & 0 & -0.227 & 0.183 \\
\hline p6 & -0.147 & 0.147 & 0.002 & -0.04 & 0.011 & 0 & 0.113 & 0.087 & 0.003 & -0.074 & 0.038 \\
\hline p7 & -0.196 & 0.312 & 0.005 & -0.181 & 0.266 & 0.006 & 0.123 & 0.123 & 0.006 & 0.172 & 0.238 \\
\hline $\operatorname{Pr}$ & 1.446 & 0.794 & 0.053 & -0.312 & 0.037 & 0.004 & -0.419 & 0.067 & 0.014 & 0.115 & 0.005 \\
\hline 01 & -0.093 & 0.267 & 0.001 & 0.061 & 0.113 & 0.001 & 0.016 & 0.008 & 0 & 0.084 & 0.219 \\
\hline $\mathrm{dl}$ & 0.122 & 0.43 & 0.003 & -0.06 & 0.103 & 0.001 & 0.091 & 0.237 & 0.006 & -0.019 & 0.01 \\
\hline il & -0.125 & 0.216 & 0.002 & 0.047 & 0.03 & 0 & -0.185 & 0.475 & 0.013 & -0.057 & 0.046 \\
\hline 02 & -0.103 & 0.332 & 0.001 & 0.05 & 0.079 & 0 & -0.093 & 0.269 & 0.003 & -0.049 & 0.075 \\
\hline $\mathrm{d} 2$ & 0.16 & 0.415 & 0.004 & -0.087 & 0.124 & 0.002 & 0.139 & 0.313 & 0.011 & 0.049 & 0.039 \\
\hline i2 & -0.092 & 0.399 & 0.002 & 0.055 & 0.141 & 0.001 & -0.077 & 0.277 & 0.004 & -0.016 & 0.012 \\
\hline 03 & -0.196 & 0.437 & 0.004 & -0.132 & 0.199 & 0.003 & 0.082 & 0.077 & 0.002 & 0.019 & 0.004 \\
\hline $\mathrm{d} 3$ & 0.111 & 0.467 & 0.002 & -0.038 & 0.056 & 0 & -0.05 & 0.095 & 0.002 & 0.081 & 0.252 \\
\hline i3 & -0.015 & 0.006 & 0 & 0.146 & 0.565 & 0.005 & 0.003 & 0 & 0 & -0.117 & 0.366 \\
\hline 04 & -0.148 & 0.165 & 0.001 & 0.03 & 0.007 & 0 & 0.061 & 0.028 & 0.001 & 0.259 & 0.51 \\
\hline $\mathrm{d} 4$ & 0.031 & 0.084 & 0 & -0.087 & 0.649 & 0.003 & 0.006 & 0.003 & 0 & -0.024 & 0.047 \\
\hline i4 & -0.014 & 0.004 & 0 & 0.181 & 0.615 & 0.006 & -0.044 & 0.036 & 0.001 & -0.057 & 0.06 \\
\hline 05 & -0.239 & 0.287 & 0.003 & -0.129 & 0.083 & 0.001 & -0.004 & 0 & 0 & 0.287 & 0.412 \\
\hline d5 & -0.071 & 0.226 & 0.001 & -0.005 & 0.001 & 0 & 0.052 & 0.123 & 0.002 & -0.078 & 0.269 \\
\hline i5 & 0.124 & 0.718 & 0.003 & 0.043 & 0.086 & 0.001 & -0.05 & 0.114 & 0.002 & -0.008 & 0.003 \\
\hline 06 & -0.043 & 0.063 & 0 & 0.055 & 0.102 & 0.001 & 0.01 & 0.003 & 0 & -0.133 & 0.59 \\
\hline $\mathrm{d} 6$ & 0.078 & 0.066 & 0.001 & -0.243 & 0.636 & 0.014 & 0.095 & 0.098 & 0.005 & 0.073 & 0.058 \\
\hline i6 & -0.043 & 0.041 & 0 & 0.172 & 0.658 & 0.008 & -0.091 & 0.183 & 0.005 & 0.028 & 0.018 \\
\hline 07 & -0.115 & 0.093 & 0.001 & -0.219 & 0.336 & 0.007 & 0.126 & 0.11 & 0.005 & -0.101 & 0.072 \\
\hline d7 & 0.226 & 0.306 & 0.007 & 0.095 & 0.053 & 0.002 & -0.258 & 0.399 & 0.028 & 010 & 0.072 \\
\hline i7 & -0.078 & 0.361 & 0.002 & 0.036 & 0.075 & 0 & 0.084 & 0.412 & 0.006 & -0.019 & 0.021 \\
\hline 08 & -0.064 & 0.131 & 0.001 & 0.077 & 0.195 & 0.002 & 0.032 & 0.033 & 0.001 & -0.119 & 0.461 \\
\hline $\mathrm{d} 8$ & 0.259 & 0.311 & 0.007 & -0.157 & 0.114 & 0.004 & -0.024 & 0.003 & 0 & 0.195 & 0.176 \\
\hline i8 & -0.087 & 0.231 & 0.001 & 0.006 & 0.001 & 0 & -0.028 & 0.025 & 0 & 0027 & 0.022 \\
\hline o9 & -0.109 & 0.132 & 0.003 & 0.027 & 0.008 & 0 & -0.187 & 0.39 & 0.028 & 0.051 & 0.029 \\
\hline d9 & 0.804 & 0.692 & 0.027 & -0.288 & 0.089 & 0.005 & -0.366 & 0.144 & 0.018 & 0.081 & 0.007 \\
\hline i9 & -0.047 & 0.011 & & 0.035 & 0.006 & 0 & 0.328 & 0.524 & 0.064 & -0.085 & 0.036 \\
\hline 010 & 0.877 & 0.75 & 0.031 & -0.175 & 0.03 & 002 & -0.213 & 0.044 & 0.006 & 0.147 & 0.021 \\
\hline d10 & -0.138 & 0.109 & 0.001 & 0.123 & 0.088 & 0.001 & -0.126 & 0.092 & 0.002 & -0.039 & 0.009 \\
\hline i10 & -0.08 & 0.492 & 0.002 & 0.008 & 0.005 & 0 & 0.033 & 0.082 & 0.001 & -0.011 & 0.009 \\
\hline 011 & 0.255 & 0.213 & 0.006 & -0.382 & 0.478 & 0.021 & 0.268 & 0.235 & 0.022 & 0.056 & 0.01 \\
\hline d11 & -0.102 & 0.541 & 0.001 & -0.018 & 0.016 & 0 & 0.076 & 0.302 & 0.003 & -0.009 & 0.004 \\
\hline ill & -0.045 & 0.037 & 0 & 0.164 & 0.479 & 0.01 & -0.153 & .416 & 0.018 & -0.017 & .005 \\
\hline 012 & -0.224 & 0.148 & 0.002 & -0.203 & 0.121 & 0.002 & -0.221 & .143 & 0.005 & -0.188 & .104 \\
\hline $\mathrm{d} 12$ & -0.161 & 0.226 & 0.001 & 0.033 & 0.009 & 0 & -0.118 & 0.121 & 0.003 & & 0.499 \\
\hline i12 & 0.039 & 0.279 & 0.001 & 0.013 & 0.032 & 0 & 0.033 & 0.204 & 0.001 & -0. & 0.08 \\
\hline 013 & -0.277 & 0.172 & 0.004 & -0.145 & 0.047 & 0.001 & -0.12 & 0.032 & 02 & 0.565 & 0.713 \\
\hline d13 & 0.225 & 0.572 & 0.007 & -0.003 & & 0 & -0.066 & 0.05 & & -0.112 & 143 \\
\hline i13 & -0.066 & 0.275 & 0.001 & 0.027 & 047 & 0 & 0.048 & 0.147 & & & \\
\hline 014 & -0.07 & 0.047 & & & & 0 & 0.26 & 0.643 & 0.021 & 0.163 & 252 \\
\hline d14 & 0.231 & 0.523 & 0.008 & 0.099 & 0.095 & 0.002 & -0.179 & 311 & 0.015 & -0.047 & 122 \\
\hline i14 & -0.127 & 0.662 & 0.004 & -0.061 & 0.152 & 0.001 & 0.007 & & 0 & -0.036 & \\
\hline 015 & & & & & & & & & & & \\
\hline d15 & 0.267 & 0.447 & 0.009 & 0.107 & 72 & 0.002 & -0.251 & 93 & 26 & -0.05 & 16 \\
\hline i15 & -0.115 & 1 & 0.003 & -0.075 & & 0.002 & 0.034 & & & -0 . & \\
\hline $\mathrm{cls}$ & 0.016 & 0.002 & & & & 0.007 & -0.078 & 0.046 & & -0.123 & 15 \\
\hline $\operatorname{cln}$ & -0.006 & 0. & 0 & -0. & & 0.001 & 0.029 & 64 & 01 & & \\
\hline $\mathrm{clr}$ & 0.032 & 0.001 & & & 6 & 01 & -0.9 & 0.671 & 0.025 & & 01 \\
\hline $\mathrm{c} 2 \mathrm{~s}$ & -0. & & 0.003 & -0. & & & -0.001 & 0 & 0 & & 158 \\
\hline $\mathrm{c} 2 \mathrm{n}$ & 0.113 & 0.382 & 0.004 & & 0.537 & 0.009 & 0.039 & 0.046 & 0.002 & -0. & 013 \\
\hline $\mathrm{c} 2 \mathrm{r}$ & -0.844 & 0.215 & 0.018 & & 0.678 & 0.084 & -0.554 & 093 & 025 & -0. & 3 \\
\hline $\mathrm{c} 3 \mathrm{~s}$ & -0.076 & 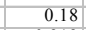 & 0.001 & -0 & & 0 & 0.145 & 56 & & & \\
\hline $\mathrm{c} 3 n$ & 0.6 & 0.2 & 0.001 & -0.004 & 0.002 & 0 & -0. & & & 0.023 & 156 \\
\hline $\mathrm{c} 3 \mathrm{r}$ & 0.042 & 0.001 & 0 & & 0.061 & 001 & -0.917 & 0.675 & 0.026 & -0.012 & 0 \\
\hline $\mathrm{c} 4 \mathrm{~s}$ & 0.08 & 0.25 & 0.002 & 0. & & 0.001 & & .096 & & -0. & 038 \\
\hline$c 4 n$ & -0.1 & 0.286 & 0.002 & & & & & & & & \\
\hline $\mathrm{c} 4 \mathrm{r}$ & & & 0 & & & 0.001 & -0.743 & & 0.018 & 0.456 & 173 \\
\hline $\mathrm{c} 5 \mathrm{~s}$ & -0.056 & 0.044 & 0 & 0.065 & 0.059 & 0 & 0.098 & 0.133 & 0.002 & -0. & 439 \\
\hline c5n & 0.004 & 0011 & 0 & -0.013 & 4018 & 0 & 0.006 & 0.024 & 0 & 00 & 372 \\
\hline $\mathrm{c} 5 \mathrm{r}$ & & & 0 & & & 0.001 & & & 25 & & 001 \\
\hline c6s & 0. & 0. & 0 & & 0. & 0 & 0.181 & 0.12 & 0.004 & -0.223 & 182 \\
\hline c6n & -0.008 & 0.0 & 0 & -0. & 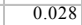 & 0 & .004 & 0004 & & 00 & 113 \\
\hline c6r & 0. & 0. & 0 & & & 01 & -0.9 & & 25 & & \\
\hline c7s & & & 0 & & & & & & & -0.021 & 0.001 \\
\hline c7n & 0.151 & 0.209 & 0.009 & 0.2 & 0.746 & 0.05 & 0.064 & 0.037 & 0.005 & 0.02 & 0.004 \\
\hline c7r & -1.145 & 0.22 & 0.073 & -2.1 & & 0.372 & -0.435 & & 134 & 0 & 03 \\
\hline c8s & & 0. & 0 & 0. & & 0 & 0 & & 07 & & \\
\hline $\mathrm{c} 8 \mathrm{n}$ & -0.006 & 0.073 & 0 & -0.007 & 0.08 & & 0.008 & 0.124 & 0 & 0.001 & 0.001 \\
\hline $\mathrm{c} 8 \mathrm{r}$ & 0.038 & 0.001 & 0 & 0.275 & 0.062 & 0.001 & -0.901 & 0.666 & 0.025 & 0.033 & 0.001 \\
\hline $\mathrm{c} 9 \mathrm{~s}$ & -0. & 0.055 & 0 & 00 & 000 & 0 & 0.045 & 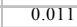 & 0 & -0.2 & 0263 \\
\hline$c 9 n$ & 0.00 & 0.0 & 0 & -0.6 & & 0 & 0.014 & & 0 & 0.024 & 0.219 \\
\hline $\mathrm{c} 9 \mathrm{r}$ & 0.038 & 0.001 & 0 & 0.275 & 0.062 & 0.001 & -0.901 & 0.666 & 0.025 & 0.033 & 0.001 \\
\hline
\end{tabular}


Table. 3b Correspondence analysis: row and column contributions - 9

clusters (continua)

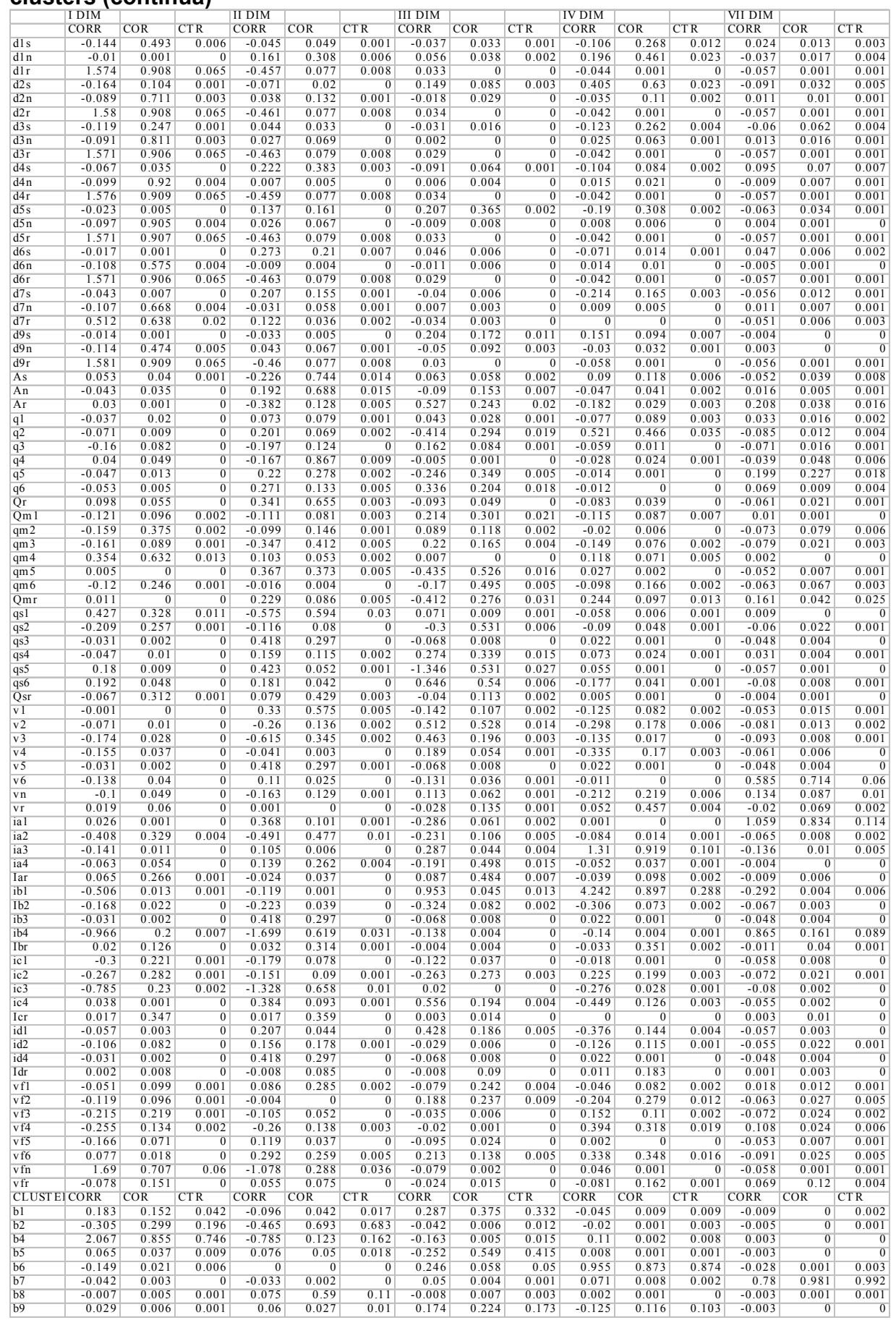

